Max-Planck-Institut für demografische Forschung

Max Planck Institute for Demographic Research

Konrad-Zuse-Strasse 1 - D-18057 Rostock · GERMANY

Tel +49 (0) 3812081 - 0; Fax +49 (0) 3812081 - 202;

http://www.demogr.mpg.de

MPIDR WORKING PAPER WP 2006-036

OCTOBER 2006

\title{
Transition to second birth - the case of Russia
}

Dorothea Rieck (rieck@demogr.mpg.de)

This working paper has been approved for release by: Gerda Ruth Neyer (neyer@ demogr.mpg.de) Deputy Head of the Laboratory of Contemporary European Fertility and Family Dynamics.

(C) Copyright is held by the authors.

Working papers of the Max Planck Institute for Demographic Research receive only limited review. Views or opinions expressed in working papers are attributable to the authors and do not necessarily reflect those of the Institute. 


\title{
Transition to Second Birth
}

- The Case of Russia -

by

Dorothea Rieck ${ }^{*}$

\begin{abstract}
This study examines the determinants of second births in Russia before and during the economic and political transition. Using data from the Generations and Gender Survey and apply the method of hazard regression, we find a strong period effect: whereas the second birth risk increased in the 1980s, it decreased significantly after 1992. This effect remains even after controlling for individual characteristics. We argue that the dramatic increase in economic and social uncertainties after the collapse of the communist system in Russia is responsible for the fertility reduction.
\end{abstract}

* Contact information: Max Planck Institute for Demographic Research, Konrad-Zuse-Straße 1, 18057 Rostock, Germany. E-mail: rieck@demogr.mpg.de 


\section{Introduction}

Since the beginning of the political and economic transition of the late 1980s and early 1990s, significant changes in demographic behavior have been observed in Central and Eastern Europe. Additional to a dramatic decline in fertility, a decrease in the number of marriages and an increase of cohabitations and extra-marital births are the main aspects of changes in family formation behavior.

Russia as well as other Eastern European countries experienced fundamental changes in the late 1980s and early 1990s. In the Soviet Union, the individual life-course was structured by social and economic policies that guaranteed a modest level of living to everybody. After the transition, under the conditions of a market economy, disparities between social groups emerged and poverty grew. These facts make a study of the different institutional changes and their effects on family formations very interesting.

The aim of this paper is to analyze the main determinants of the second birth risks of Russian women, applying an event-history analysis. Whereas in the 1980s Russia tended to be a two-child-society (50 percent of women had two children), fertility dropped sharply after the political and economic transition, especially owing to a reduction in second order births. This drop makes an analysis of the event meaningful.

The paper is structured as follows: after a summary of recent demographic and socio-economic developments in Russia, we continue with a brief description of the institutional framework. Following some theoretical considerations, we introduce the data set, the method used and our working assumptions in the context of our explanatory variables. We present our results in the empirical part and close with some concluding remarks.

\section{Demographic and Socio-Economic Changes of the Last Decades}

One of the main characteristics of the population development in Russia over the last twenty years is the dramatic decrease in the number of births. In the 1980s, the TFR fluctuated around the replacement level and increased to 2.23 in 1987 owing to the pronatalist policies of the Soviet Union, which included partially-paid maternity 
leave and other special conditions and benefits for families with more than two children (Zakharov and Ivanova 1996). Starting after 1987, the TFR began to decline (Figure 1). In 1999, the TFR reached its lowest level: 1.17. The CRF, by contrast, was relatively stable around 1.8 for the cohorts born between 1940 and 1960 . Nevertheless, the CFR for cohorts born after 1960 declined too but not as drastically as the TFR. ${ }^{2}$ The development of the TFR and CFR and an increase in the mean age at childbirth (from 24.6 in 1994 to 26.1 in 2002 for all births) may be an indication for a postponement effect (Veselkova and Sagradov 1995).

Figure 1: Total Fertility Rate and Completed Fertility Rate

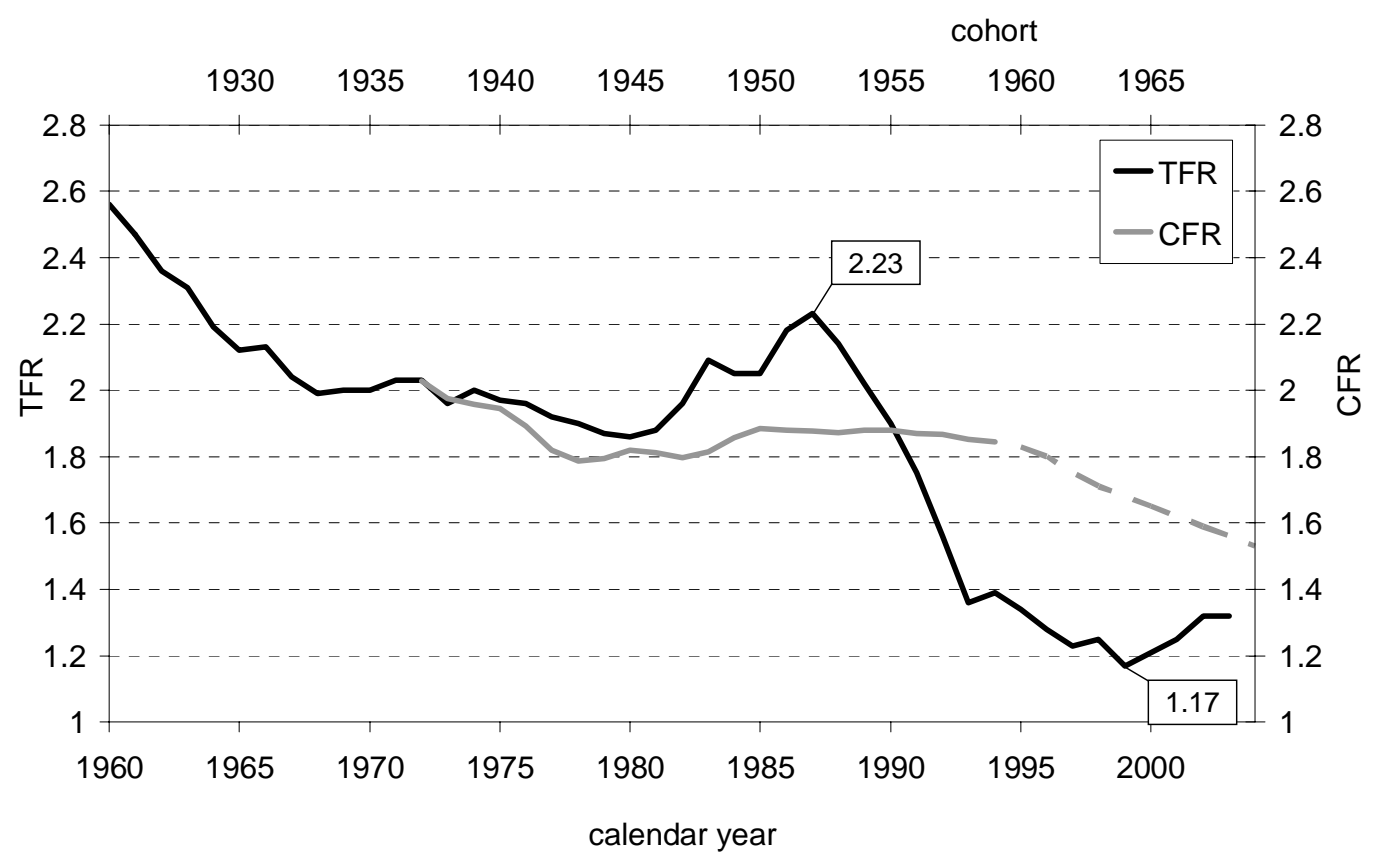

Source: Council of Europe 2004; Frejka \& Sardon 2004

Besides these characteristics, other aspects are worth mentioning: a decrease in the number of marriages and rising numbers of cohabitations. The number of extramarital birth nearly doubled between 1990 and 2000.

The onset of transformation from a planned economy to a market economy in the 1990s is mentioned as a main reason for the changes in fertility patterns. Transformation disrupted the established economic system and led to a serious

\footnotetext{
${ }^{2}$ The data on the 1960s and later cohorts are estimated by Frejka and Sardon (2004).
} 
economic and labor market crisis. The Soviet Gross Domestic Product declined by 17 percent in 1991 and was further dropping at an accelerating rate. Inflation was becoming a major problem. Between 1990 and 1991, prices for goods increased by 140 percent (Kohler and Kohler 2002). The government reacted to these developments by lifting price controls and reducing government spending, targeting outlays for public investment projects as well as for produces and consumer subsidies. In 1992, these policies resulted in an inflation rate of over 300 percent (Szivos and Giudic 2004, Shorrocks and Kolenikov 2001). Since wages did not increase analogously, real income decreased by more than 50 percent in the same year. For Russians, these developments entailed a drastic decline in living conditions. The proportion of people living below the poverty line increased to 35 percent of the population in 1999 (Shorrocks and Kolenikov 2001). Unemployment rose steeply in the 1990s. Unemployment did not exist in times of the totalitarian regime, at least officially. In 1992, however, the unemployment rate was 5.6 percent and nearly doubled to 10.8 percent in 1998 (Mroz et al. 2004). Children or rather, families with children were particularly affected by these developments. Before the transition, more Russian women participated in the labor force than in almost any other country in the industrialized world. In almost every case did women in the Soviet Union work full time. Less than one percent of the work force was employed part-time (Lokshin 2004).

\section{The Institutional Framework}

Institutional conditions changed fundamentally after 1990. Preceding transition, public childcare, parental leave, and monetary support enabled Russian women to combine work with having children. Following transition to the market economy, the system of social security suffered a deep crisis.

One of the main components of state support to families in the Soviet Era was the provision of public childcare facilities. Whereas in the late 1980s, about 70 percent of children aged between one and six years were registered in public childcare institutions, the proportion of children in preschool facilities dropped by more than 50 percent between the 1980s and the mid-1990s. One reason for this development is the increase in the costs of childcare. In Soviet times, the costs for childcare services were 
partly or fully covered by subsidies from federal and local government or by funding from employers. After 1990, all government child support programs were suspended and only a few companies now can afford to support childcare services (Lokshin 2004). Today, the costs for childcare make up a major part of a household's budget.

Another characteristic of family policy is parental leave. It enables parents to keep their salary and job while caring for their children. In Russia, parental leave is provided for mothers only. Maternity leave is provided for employed women 70 days before and 70 days after childbirth. During maternity leave, mothers receive 100 percent of their last income. Unemployed mothers receive the minimum wage (OECD 2001). Childcare leave in Russia is limited to 18 month and is granted to employed women, students, and military service personnel (ISSA 2004). Additional to nonmonetary support and benefits during maternity leave, women receive child benefit to the amount of 500 rubles until the child is 18 month old. Employed women receive an additional benefit at childbirth that is 15 times the minimum wage. After the first 18 months, childcare benefit is granted only to families, whose income is below the subsistence level (ISSA 2004). Appendix 1 provides an overview of family policies before and after the transition.

The institutional framework in Russia gives to parents little incentive to have children. The childcare services are very cost-intensive. The childcare benefits are low and last for a short time only.

\section{Theoretical Framework and Hypothesis}

The prevailing explanations of changes in fertility patterns can be grouped into three main approaches, linking the recent fertility trends to economic, social, and political transformation.

The "economic crisis argument" focuses on three factors in explaining changes in fertility behavior. Firstly it is argued that a drastic increase in economic uncertainties, such as a rising unemployment or decreasing wages, is responsible for the postponement of or reduction in fertility.

After the transition, economic uncertainties in Russia rose as a result of rising employment uncertainties, decreasing real wages, and reductions in state support for 
parents and especially support for mothers, who want to combine work with the responsibilities of looking after a family. In her study on the rise of female unemployment (in East Germany) and the decline of child and maternal support from the state, Adler (1997) concludes that a shift in the dependency of mothers from the state to male partners has taken place and argues that the relation between rising uncertainties and falling fertility is due to collective behavior resulting from a "new survival culture", the latter which includes abstinence from marriage and motherhood or a kind of social protest against the institutional changes, which lowered women's independence and security (Adler 1997).

Relative deprivation is another social and economic aspect that may have an impact on fertility behavior. It means that people assess their income as low relative to others or to their personal expectations, and that they view their economic situation as not conducive to have a (another) child (Philipov 2002). For example, people who have gained a higher level of education than others may feel deprived because they receive a lower income than before.

Here, the impact of longer education on dropping fertility becomes clear. Human capital becomes increasingly important particularly in times of employment uncertainties. In many Eastern European countries, a significant increase in the education enrollment rate and time spent in education has been witnessed. In line with traditional economic theories, a higher educational level and the outcomes - the preference to pursue a job career - as a result of, women often postpone family formation. Educational expansion and its effect on job commitment will keep fertility low (Philipov 2002).

Rising costs of children and its impact on fertility behavior should be taken into account, too. Caused by institutional changes after the collapse of the communist system, increasing costs of child care, reductions in state support for families, and a decline in real wages, the direct costs of children escalated.

In line with the argumentation of Gary S. Becker, increasing costs of children lead to the substitution of the number of children by high quality children.

In the context of the impact of economic circumstances on fertility, the theory of Gary S. Becker should be concretized. In general, Becker applies the microeconomic theory of consumption to fertility behavior. Becker's approach sees children as consumption goods and assumes that couples, being rational acting persons, liken the costs and benefits of children to consumption goods. The benefit of 
children is defined in terms of their quality and quantity. Moreover, Becker argues that the demand for children increases with increasing income. However, this does not necessarily mean that the number of children increases. If parents want to have "higher quality" children, they make larger financial investments into their quality than into their quantity (Becker 1960). Nevertheless, it is not only monetary aspects that influence the decision for or against children but also non-monetary aspects like time or human capital. Now, besides income the demand for children depends on the relative costs of children. Following Becker, the drop in fertility is the result of increasing opportunity $\operatorname{costs}^{3}$, due to higher educational attainment and higher laborforce participation of women.

What does this mean applied to the Russian context? Is Becker's theory broad enough to apply to the special case of Russia?

Before 1990, families with children received many monetary and nonmonetary benefits. With the end of the communist system, large social and institutional changes led to the collapse of the social security system, and for parents the decision to postpone or delay childbirth became more likely.

Concerning the opportunity costs of children, we need to consider that before the collapse of the system Russian women largely participated in the labor-force. The opportunity costs were relatively low due to the system of child-care support. After 1990, child-care benefits decreased and employment uncertainties increased. We can assume that nowadays the opportunity costs are higher, because re-entry into the labor market of women who previously were on maternity leave is much more uncertain and because state benefits to substitute income loss are uncertain, too.

The second approach, the "adaptation approach", sees transformation as constituting a convergence process towards "western" social and economic incentives for childbearing and does not emphasize economic difficulties and the crisis associated with changes in fertility behavior (Kohler and Kohler 2002). This explanation has been proposed to apply particularly to East Germany (Kreyenfeld 2001).

Is it possible to apply similar assumptions to other Eastern European countries? Compared to these countries, the case of East Germany is unique. For

\footnotetext{
${ }^{3}$ Opportunity costs mean a loss utility caused by the choice of another option.
} 
example, between 1989 and 1992 the TFR dropped by 47 percent, whereas in Russia, Bulgaria, and Romania the TFR declined by approximately 20 percent. Similarities have been observed by Conrad et al. (1996) for marriage rates. The authors argue that the reason behind this development is the radical transformation of the institutional, economic, and psychological environment, a rational response to and the incremental adaptation of the new incentive structure regarding family formation.

As to "ideational changes", our third approach, they denote changes in norms, values, and attitudes that cause consequential modifications in fertility behavior. The main assumption is that demographic trends occur due to the "second demographic transition" (Lesthaeghe 1992, van de Kaa 1987), which transforms fertility behavior to becoming more secular and individualistic. This explanation attempts to separate the socio-economic transformation from the demographic changes of the last decades. Following this assumption, Russia, as well as other Eastern European countries experience the fundamental changes that Western European countries have experienced in the 1960s (Vishnevsky 1996, Zakharov 1999). The approach implies that the fertility decline of the last 20 years in Russia will be permanent and that a return to fertility patterns like before the transition is unlikely.

The criticism on this approach, especially regarding the particularities of the Eastern European countries, is various. Firstly, it is argued that changes in norms and values are a long standing process and must have started their development before the transition period. Changes in the pre-1990 period are unlikely to have taken place because the totalitarian regime of the former communist states favored conformism and alienation rather than individualism and autonomy (Philipov 2002). On the other hand, some modern values, for example female autonomy and female labor-force participation, were widely spread. Furthermore, it is argued that the discontinuity and anomie of the 1990s created the conditions for a sudden ideational change, which is different from the diffusion or long-term developments described above.

Following this argumentation, interdependency between the economic and the ideational approach to explain the fertility transition in Eastern Europe is likely.

In this paper, we investigate the "economic crisis" argument and besides the general demographic variables we focus on the educational level of women as a corevariable to explain fertility development in Russia. 
Women's education is one of the main characteristics that explain family formation behavior. With regard to the theoretical consideration, and in particular concerning the economic theories, we conclude the following:

In general, we assume that the educational level has a significant impact on the fertility in Russia, especially after the start of the transition.

After the transition, educational differences play a much more crucial role than in pre-transition times. During the communist period, educational differences did not inevitably lead to different employment characteristics in the labor-force participation or in wages. Following the transition, the situation is quite different. Due to economic uncertainties (low wages, high unemployment) women are intend to pursue higher education in order to have higher earnings, lower unemployment risks, as well as better job prospects in general. These factors as well as rising costs of child-rearing, and restrictions in childcare support are reasons to spend more time doing other activities and postpone or delay family formation.

As to Russia, we assume that due to labor-market uncertainties and rising demands for human capital, the educational level becomes increasingly important. We expect lower second birth intensities for higher educated women, who are more career oriented and have higher opportunity costs. Furthermore, we consider that education enrollment is incompatible with having children. For the second birth we assume lower birth risks for women that are "in education".

\section{Data and Method}

\subsection{Data Set}

The study uses data from the "Generations and Gender Survey". The survey form part of the Generations and Gender Programme (GGP). The latter is a system of national Generations and Gender Surveys and contextual databases on several European and some non-European countries. It is a comparative, multidisciplinary, retrospective, as well as a prospective study. The aim is to improve the understanding of demographic and social developments in these countries and of the factors that influence these developments. A special focus of the survey is that it highlights the relationships between partners as well as the relations between children and their 
parents. The program furthermore focuses on the determinants of the transitions in these relations, marked by demographic events, such as leaving the parental home, the formation and dissolution of partnerships, and childbirth (Vikat et al. 2005). The first wave of the Russian GGS provides complete fertility and family formation histories, for the second wave complete educational and employment histories are planned.

The dataset we use is the Russian GGS. It was conducted between June and August 2004. A total of 4,223 men and 7,038 women between the ages of 18 and 79 were interviewed.

Our study analyzes Russian women between ages 14 and 45. The sample consists of women who had at least one child and were at risk of having a second child. The total sample size (after cleaning our data, see Appendix 2) is 5,797 and second births total $2,547^{4}$.

\subsection{Method}

For the purpose of our analysis, we apply event-history techniques. Multiplicative piece-wise constant hazard-regression models are estimated to measure second birth intensities $(\mu)$ for Russian women. These intensities are influenced by various covariates, for example age at first birth or marital status.

The process time starts at the date of the first birth and ends with the date of the birth of the second child. Cases are also censored at age 45 or at the date of interview if the respondent did not have a second child.

The baseline hazard (the basic time factor) is duration since the birth of the first child. We use a piecewise constant model, so that the basic time factor is defined as a categorical variable. The hazard rates are constant in the categories, but they can vary across them. We control for various time-constant and time-varying covariates that are categorical, too.

${ }^{4}$ Some cases were deleted before the start of the analysis, for example cases with twins at first birth, stepchildren, adopted and fostered children and when the first child was born the mother turned 14. 
The model that contains our main effects is written as follows:

$$
\mu(t)_{i j k l m n}=a_{i(t)} * b_{j(t)} * c_{k} * d_{l(t)} * e_{m(t)} * f_{n},
$$

where $a$ represents the effect of the time factor and $i(t)$ denotes the intervals in which the baseline hazard is assumed to be constant (0-12, 13-24, 25-36, 37-48, 4960, 61-72, 73-120 and 121-180).

Factor $b(t)$ is the effect of the calendar period (time varying),

Factor $c$ denotes the effect of age at first birth (time constant),

Factor $d(t)$ captures the effect of the marital status (time varying),

Factor $e(t)$ is the effect of education (time varying), and

Factor $f$ denotes the effect of the number of siblings (time constant).

\subsection{Covariates}

Our model contains three time-constant covariates, three time-varying covariates and the baseline hazard.

To investigate the influence on second birth risks, we select the time-varying covariates marital status (partnership history), period and the educational level. The time-constant covariates are age at first birth and the number of siblings. Tables 1 and 2 give an overview of the data sample used. 
Table 1: Distribution of respondents according to the various levels of the time-fixed covariates

\begin{tabular}{|c|c|c|c|c|c|}
\hline \multirow[t]{2}{*}{ Variables } & \multirow[t]{2}{*}{ Occurrences } & \multicolumn{2}{|c|}{ Exposures } & \multirow[b]{2}{*}{$\begin{array}{l}\text { Number of } \\
\text { respondents }\end{array}$} & \multirow[b]{2}{*}{ per cen } \\
\hline & & $\begin{array}{l}\text { person- } \\
\text { months }\end{array}$ & per cent & & \\
\hline \multicolumn{6}{|l|}{ Age at first birth } \\
\hline $14-19$ & 492 & 129,561 & 15.35 & 1,090 & 18.79 \\
\hline $20-24$ & 1,528 & 431,575 & 51.13 & 3,168 & 54.61 \\
\hline $25-29$ & 457 & 184,872 & 21.90 & 1,096 & 18.89 \\
\hline $30-34$ & 62 & 71,321 & 8.45 & 328 & 5.65 \\
\hline $35+$ & 9 & 26,659 & 3.16 & 119 & 2.05 \\
\hline Total & 2,548 & 843,988 & 100.00 & 5,801 & 100.00 \\
\hline \multicolumn{6}{|l|}{ Number of siblings } \\
\hline No siblings & 330 & 142,976 & 16.94 & 867 & 14.94 \\
\hline One or two sibling(s) & 1,304 & 405,285 & 48.02 & 3,002 & 51.75 \\
\hline Three or more siblings & 907 & 292,934 & 34.71 & 1,919 & 33.08 \\
\hline Missing & 7 & 2,793 & 0.33 & 13 & 0.24 \\
\hline Total & 2,548 & 843,988 & 100.00 & 5,801 & 100.00 \\
\hline
\end{tabular}

Source: author's estimations based on the Russian GGS

Table 2: Distribution of time at risk according to the various time-varying covariates

\begin{tabular}{|c|c|c|c|}
\hline Variables & Occurrences & $\begin{array}{l}\text { Expc } \\
\text { person- } \\
\text { months }\end{array}$ & $\begin{array}{l}\text { Ires } \\
\text { per cent }\end{array}$ \\
\hline \multicolumn{4}{|l|}{ Education } \\
\hline No or low degree & 391 & 156,761 & 18.57 \\
\hline Medium degree & 1,515 & 462,527 & 54.80 \\
\hline High degree & 414 & 160,888 & 19.06 \\
\hline In education & 225 & 63,085 & 7.47 \\
\hline Missing & 3 & 727 & 0.09 \\
\hline Total & 2,548 & 843,988 & 100.00 \\
\hline \multicolumn{4}{|l|}{ Period } \\
\hline Until 1968 & 539 & 104,418 & 12.37 \\
\hline $1969-1976$ & 385 & 99,396 & 11.78 \\
\hline $1977-1980$ & 195 & 64,771 & 7.67 \\
\hline 1981-1984 & 278 & 76,452 & 9.06 \\
\hline $1985-1988$ & 348 & 80,863 & 9.58 \\
\hline 1989-1992 & 294 & 87,499 & 10.37 \\
\hline 1993 and later & 509 & 330,589 & 39.17 \\
\hline Total & 2548 & 843,988 & 100.00 \\
\hline \multicolumn{4}{|l|}{ Marital status } \\
\hline Single & 118 & 94,193 & 11.16 \\
\hline Cohabitation & 135 & 63,785 & 7.56 \\
\hline Marriage & 2,216 & 512,056 & 60.67 \\
\hline Divorced/widowed & 77 & 171,026 & 20.26 \\
\hline Missing & 2 & 2,928 & 0.35 \\
\hline Total & 2,548 & 843,988 & 100.00 \\
\hline
\end{tabular}


Below we describe the time-varying and time-constant covariates and our expectations about the influence of the covariates on second birth risks.

\section{Educational level}

Unfortunately, the first wave of the GGS does not have complete education histories as only the highest educational level at the time of interview and the month and year of the completion of the first and second education is reported. In order to construct a time-varying covariate for the educational level, we coded the respondents as being in education throughout the time before they attained the educational level reported in the survey. After the date of education completion, we coded respondents as being out of education (Hoem \& Kreyenfeld 2006). Respondents with a vocational certificate as their highest educational level were coded as being "in education" until they have obtained the certificate. After education completion, we coded the educational level as "medium degree". Correspondingly, respondents with a university degree were coded as being "in education" until completion of the university degree and after that as "higher degree".

The educational levels we classified into three groups, using ISCED 76 (the International Standard Classification of Education):

1. no or low degree $=$ no degree or at least in education until age 16 ,

2. medium degree $=$ vocational courses; initial and intermediate professional education degrees without and with secondary education degrees; technical trade school; technical, medical, musical, pedagogical, arts school,

3. higher degree $=$ university degrees or correspondent degrees (institute, academy, graduate school).

Today, young women stay longer in the educational system than did women of older cohorts. A higher educational level increases the probability of establishing a stable career and this provides a reduction in life uncertainties, which is particularly important in times of economic and social uncertainties. Following this, we assume that with higher education second birth risks increase. But after 1990, the situation is different. As discussed in Section 4, we assume that highly education women have lower second birth risks than their lower educated counterparts and that women in education also have lower risks of having a second child.

Age at first birth 
Another factor that influences second birth risks is age at first birth. The mean age of first birth in Russia has been increasing since 1994. The changed time schedules of educational participation, which means that women stay longer in the educational system, is one of the major factors of birth postponement, especially of first birth. Caused by biological limitations, one assumption is that women who give first birth relative late in life have the second child faster. This should increase second birth intensities. But we assume that in the Russian context, a delay of second birth is more likely. Following this, we expect a negative correlation between age at first birth and second birth risks.

\section{Period}

The covariate that investigates the influence of calendar time describes the impact of changing family policies as well as times of economic and political change. Before the Russian political, economic and social transition, state support for families with children was characterized by non-monetary supports such as good structured childcare services and childcare allowance. Particularly the 1980s were characterized by pronatalist policies, which led to an increase in the TFR. After 1990, social and economic state support for families was drastically reduced. In addition, economic and social uncertainties increased. Following this, we expect lower second-birth risks for the post-transition period.

\section{Marital status}

In Russia an increase of extra-marital birth has been observed. In connection with the decrease of first marital rates and increasing numbers of cohabitations this may be an evidence for a change in values concerning marital behavior on the one hand. On the other, the rising economic uncertainties may explain the increasing number of out-of-wedlock births. As mentioned above, in case of an income below the subsistence level single parents receive more childcare allowance than married parents. Nevertheless, we assume a positive correlation to exist between second birth risks and marriage. We expect lower second birth risks for divorced or widowed women and for single women as well.

For the purpose of our study, we freeze the marital status seven months before the second birth because we assume that knowledge about a pregnancy influences the marriage behavior of the persons concerned. If many women marry shortly before delivering their second child, this would bias the effect of marital status. 


\section{Number of siblings}

The number of siblings may also have impact on fertility behavior. Experiences made with siblings in the family of origin influence a person considerably. The number of siblings may be a measure of kinship support and so a high number of siblings may contribute to a reduction in social uncertainties. Because of these factors, we assume that women with several siblings have a higher second birth risk than women with no siblings.

\section{Results}

Figure 2 displays the absolute second-birth risk measured in months since the birth of the first child. Russian women have the highest risk of having a second child when the first one is between 4 and 6 years of age.

Figure 2: Absolute risk per 1,000 person-months

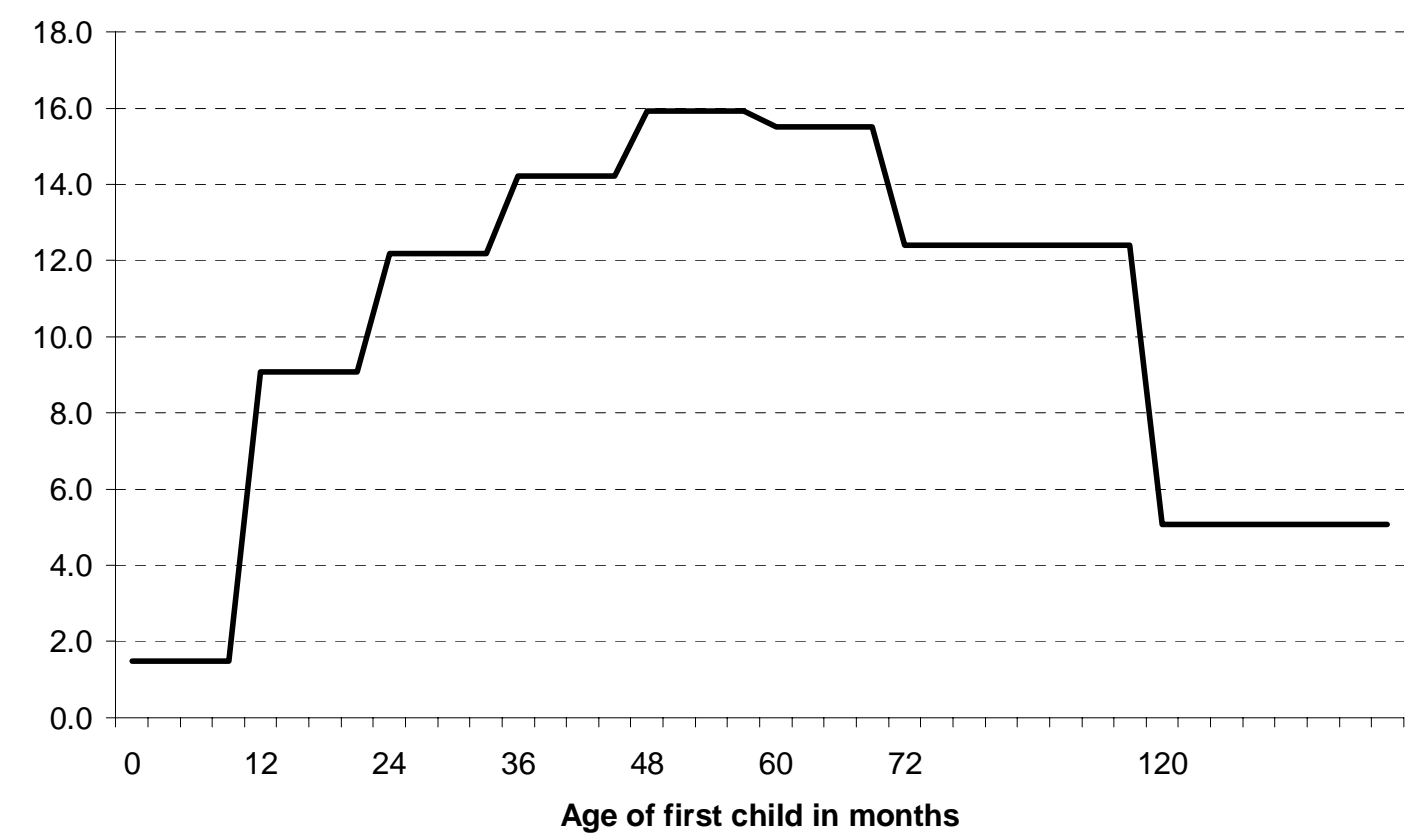

Source: author's estimations based on the Russian GGS

Note: controlled for period, age at first birth, marital status, education and the number of siblings 
Table 3 presents estimations of the final model for the second-birth risk of Russian women. Firstly, we analyzed the influence of period effects on second birth risk. For the 1977-1980 period we find a significant lower risk of 40 percent (reference category: period between 1985 and 1988). As expected, the highest second birth risk is in the 1985-1988 period. For the 1989-1992 period, we find a 19 percent lower risk of having a second child. Furthermore, we find a highly significant lower second birth risk for the period after 1992: the risk is lower by 55 percent than for the reference group. This finding is in line with the "economic crisis argument", which holds that increasing social and economic uncertainties are responsible for the reduction in or the postponement of fertility. Furthermore our result supports the hypothesis that there is a strong negative influence of economic and social uncertainties after the collapse of the communist system in Russia on second birth risk.

Demographic variables, such as the age of the mother at first birth, also play an important role in explaining the transition to second birth. As expected, the risk of having a second child is significantly lower in all age groups after age 24 (reference category). In the first group (14-19 years), the risk is slightly, but not significantly, higher than in the reference group. Regarding our assumption, the later a women starts with childbearing, the lower is the risk to have a second child.

Our results show that the risk of having a second child is nearly twice as high for married women as for cohabiting ones. Single mothers and divorced or widowed women also have a lower second birth risk than married women. This result possibly means that the rapid increase in out-of-wedlock births mainly affect first births.

For educational attainment, we find that women with lower or no educational degree have a higher risk of having a second birth compared to the reference group, women with medium degree. Women with a higher educational degree have a lower second birth risk than women with a medium degree. The results are not significant but correspond in general with our hypothesis.

The number of siblings influences the second birth risk as expected. Women who have no siblings have a 20 percent lower risk of second birth than their counterparts with one or two siblings. The risk to have a second child is highest for women with three or more siblings. Both results are significant. 


\begin{tabular}{|c|c|c|}
\hline Level & relative risk & absolute risk \\
\hline \multicolumn{3}{|c|}{ Time since first birth } \\
\hline$<1$ year & 0.16 & 1.47 \\
\hline $1-2$ years & 1 & 9.08 \\
\hline $2-3$ years & 1.34 & 12.19 \\
\hline $3-4$ years & 1.57 & 14.23 \\
\hline $4-5$ years & 1.75 & 15.94 \\
\hline $5-6$ years & 1.71 & 15.53 \\
\hline $6-10$ years & 1.37 & 12.41 \\
\hline $10-15$ years & 0.56 & 5.08 \\
\hline$>15$ years & 0.04 & 0.38 \\
\hline \multicolumn{3}{|l|}{ Period } \\
\hline Until 1968 & $0.77 * * *$ & \\
\hline 1969-1976 & $0.70 * * *$ & \\
\hline $1977-1980$ & $0.60 * * *$ & \\
\hline 1981-1984 & $0.76 * * *$ & \\
\hline $1985-1988$ & 1 & \\
\hline 1989-1992 & 0.91 & \\
\hline 1993 and later & $0.45^{* * *}$ & \\
\hline \multicolumn{3}{|l|}{ Age at first birth } \\
\hline $14-19$ years & 1.04 & \\
\hline $20-24$ years & 1 & \\
\hline $25-29$ years & $0.81 * * *$ & \\
\hline 30-34 years & $0.29 * * *$ & \\
\hline $35+$ years & $0.11 * * *$ & \\
\hline \multicolumn{3}{|l|}{ Marital status } \\
\hline Single & $0.49 * * *$ & \\
\hline Cohabitation & $0.56 * * *$ & \\
\hline Marriage & 1 & \\
\hline Divorced/widowed & $0.65 * * *$ & \\
\hline \multicolumn{3}{|l|}{ Education } \\
\hline No or low degree & 1.07 & \\
\hline Medium degree & 1 & \\
\hline High degree & 0.98 & \\
\hline In education & $0.74 * * *$ & \\
\hline \multicolumn{3}{|l|}{ Number of siblings } \\
\hline None & $0.79 * * *$ & \\
\hline One or two & 1 & \\
\hline More than three & $1.11 * *$ & \\
\hline Log likelihood & -5595.03 & \\
\hline
\end{tabular}

Notes: (1) Time since first birth is displayed as risks per 1,000 person-months

(2) $* * * \mathrm{p} \leq 0.01 ; * * 0.01 \leq \mathrm{p} \leq 0.05 ; * 0.05 \leq \mathrm{p} \leq 0.10$

(3) Missing values are not shown but were controlled for 


\section{The effect of education on second-birth risks}

As we assume in our hypotheses, there may be a tempo effect for highly educated women. This means that due to a longer education period and biological limitations, highly educated women have their second child faster after the first one than their lower educated counterparts. To analyze this, we use an interaction between education and the age of the first child. The results do not show such an effect: the curve for the highly educated women is not shifted to the left. As Figure 3 displays, we only find a weak tempo effect for lowly educated women. Furthermore, we do not find any tempo effect between the educational groups.

Figure 3: Relative risk of second birth by education of the mother and age of first child



Source: author's estimations based on the Russian GGS

Note: Controlled for period, age at first birth, marital status and the number of siblings

Notable is the relatively high second birth risks for women in education. This result possibly is an indicator for a good compatibility between having children and education participation but the results for the educational level "in education" are not significant 
Another assumption regarding the educational level and the calendar time was that after the transition a higher educational level has a negative influence on second birth risk. Figure 4 shows such an effect. The reason for this may be the increasing opportunity costs of children.

During the 1980 periods, second birth risks increased. We assume that pronatalist policies (see section 3), which provided good compatibility between family and work, were responsible for this development. Especially for highly educated women, these measures continue to have an effect: for the 1989-1992 period, the second birth risk is highest for this group.

After 1992, the risk of having a second child decreases drastically for all educational groups. The most intensive decrease we observe for women with a high educational level. Whereas highly and medium educated women have a higher second birth risk than lower educated women in all periods (the result for highly educated women in the 1985-1988 period is not significant), the situation is the opposite in the post-1992 period. Here, highly educated women have the lowest second birth risk (with the exception of women who are in education). We assume the reason for this to be increasing economic and social uncertainties. On the one hand, the opportunity costs increased dramatically as a consequence of worsening childcare conditions and declining child- and childcare benefits; on the other hand, due to increasing unemployment and decreasing wages two-earner-households have become increasingly necessary. The consequence of this development is reflected in low second-birth risks. 
Figure 4: Relative risk of second birth by education of the mother and period

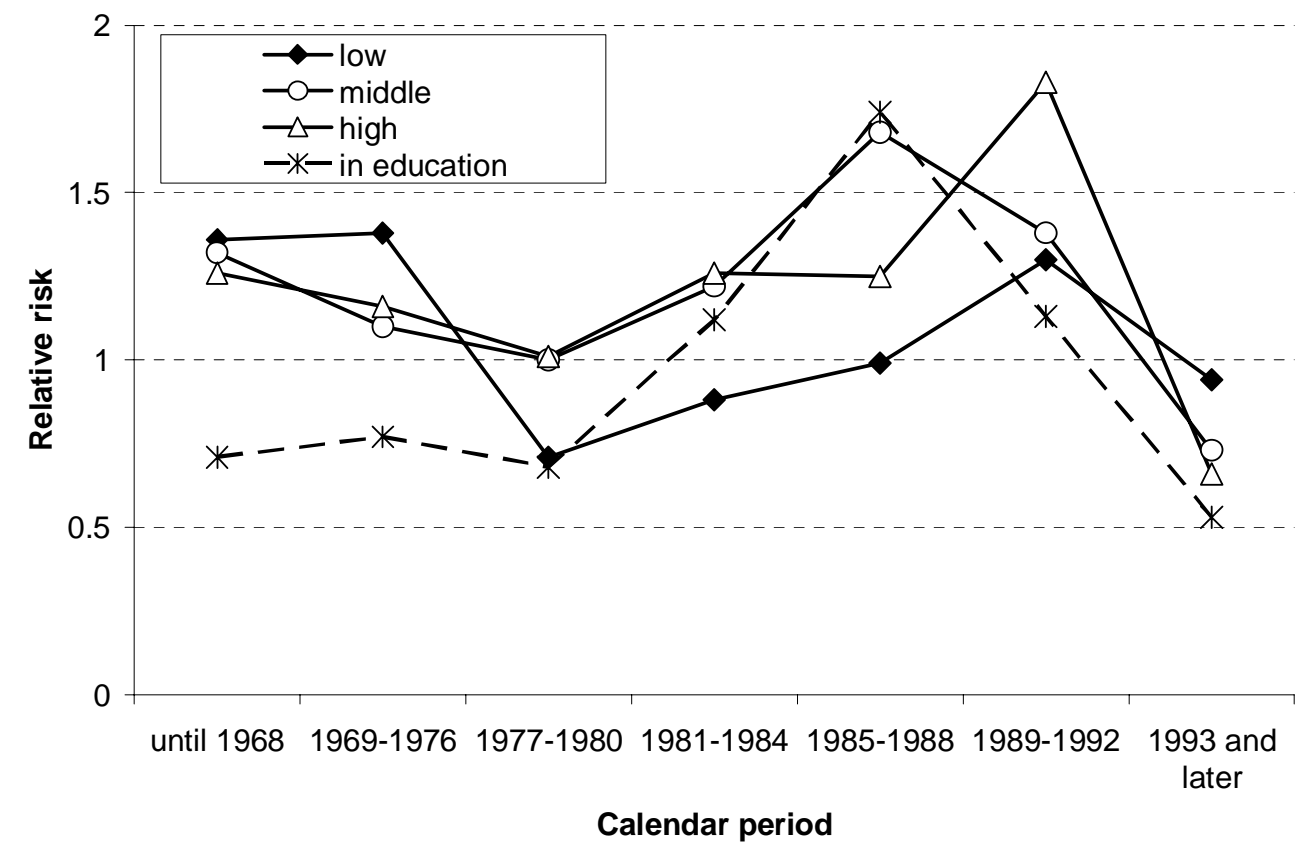

Source: author's estimations based on the Russian GGS

Note: Controlled for age at first birth, marital status and the number of siblings.

Concluding we can say that the period effect, which highlighted the influences of economic and political changes, is the most important effect in our analysis of second birth risks.

\section{Conclusions}

The paper aimed at investigating second birth risks of Russian women. To analyze the effect on these risks, we estimated a stepwise constant intensity-regression model. The analysis showed a strong period effect on second birth risks. After controlling for several covariates, we found a significant higher risk of having a second child as to the 1980 periods. We believe that this result is caused by the pronatalist policies pursued during these periods. In the Soviet Era, a network of public childcare, parental leave and financial benefits enabled women to reconcile working live with being a mother. Moreover, the state regulated the labor market in that it guaranteed the full-time employment of women, in that there was no unemployment and in that wage grids were relatively fixed and did not have serious 
influence of women's return in the labor market, their further employment or earnings.

For the post-transition period, we found that the risk of having a second child is significantly lower than for the reference group (1985-1988). As for the former periods, we assume that the reason for this development is the institutional setting. After the transition, the institutional conditions changed dramatically. One of the most important factors is the increase in the costs for childcare. Former governmental supported childcare programs were eliminated and monetary support decreased. Furthermore, the transformation process led to a serious economic and labor market crisis. As consequences of this development, the real wages declined and unemployment increased dramatically. For most Russians, this meant a serious reduction in living conditions and families with children were affected in particular. Altogether, the economic and institutional conditions provide only little incentive to have children.

To conclude, our results are in line with the "economic crisis argument", which holds in general that the increase in economic uncertainties is responsible for the reduction or the postponement of fertility.

Another argumentation of the economic explanation of fertility decline is the influence of education. Regarding the increasing importance of human capital in times of economic uncertainties, it is argued that a higher educational level and therewith often the preference for a certain job career lead to postponement of or a delay in family formation. In line with this argumentation, our hypothesis was that for higher educated women the compatibility between family and work has become more complicated following transition. Due to increasing opportunity costs of children, we assumed a lower second birth risk for highly educated women for the post-1990 period. Our results partly support this hypothesis. Whereas in the 1980s, the second birth risks for medium and higher educated women are higher than for their lower educated counterparts, the risks are decreasing in the years 1993 and later. The decrease is strongest for highly educated women. It is remarkable that in the 19891992 period the second birth risk is highest for highly educated women. We interpret this as the continuing influence of the pronatalist policies of the 1980s.

Another hypothesis assumed a timing effect for highly educated women caused by longer educational enrollment and biological limitations. We did not find 
such an effect. This means that higher educated women do not have their children closer together than lower educated women.

The other major findings on our demographic variables can be summarized as follows:

- The older a woman is at the birth of her first child, the lower is her risk to have a second birth.

○ Married women have a 44 percent higher second birth risk than women who live in cohabitation. Single mothers as well as divorced and widowed women have a significant lower second birth risk than married ones.

○ The risk of having a second child is higher for women who have siblings. For women with three or more siblings, the risk is highest.

Our study mainly investigated period influences on second birth risks of Russian women. The results showed lower second birth risk in the years after economic and political transition. What we do not know at present is whether this fertility drop is related to a postponement of having a second child or to delaying childbearing after the first child. One may arrive at a solution to this problem when the 1970s cohorts complete their fertility period.

Furthermore, an analysis of influences other than economic ones may provide deeper insights into fertility decline after the transition period. Do we have a convergence process towards "western" social and economic incentives for childbearing or are the modifications in fertility behavior related to changes in norms, values and attitudes? An investigation of these factors related to the fertility drop may be useful in order to receive a deeper understanding of fertility decline in Russia following political and economic transition. 


\section{Acknowledgements}

This study was prepared at the International Max Planck Research School of Demography during the winter-semester of 2005/06. I am grateful to Jan Hoem, Michaela Kreyenfeld and Rainer Walke for their useful teaching. I would also like to thank Hill Kulu, Dirk Konietzka, Nadja Milewski, Magdalena Muszynska and some anonymous reviewers for very insightful comments and suggestions on this work and Susann Backer for the valuable language editing of this paper. 


\section{References}

Adler, M. A. (1997). Social change and declines in marriage and Fertility in Eastern Germany. Journal of Marriage and the Family, 59 (1): 37-49.

Becker, G. S. (1960). An economic analysis of fertility. Princeton: Princeton University Press.

Conrad, C., Lechner, M. and Werner, W. (1996). East German fertility after unification: crisis or adaptation? Population and Development Review, 22(2): 331-358.

Council of Europe (2004). Recent demographic developments in Europe 2004. Strasbourg: Council of Europe Publishing.

David, H. P. (1982). Eastern Europe: Pronatalist policy and private behavior. Population Bulletin, 36 (6): 1-47.

Frejka, T. and Sardon, J.-P. (2004). Childbearing trends and prospects in low fertility countries - A cohort analysis. Dodrecht, Boston, London: Kluwer Academic Publishers.

Hoem, J. M. and Kreyenfeld, M. (2006). Anticipatory analysis and its alternatives in lifecourse research. Part 1: Education and first childbearing. MPIDR Working Paper, WP-2006-006.

International Social Security Association (ISSA) (2004). Social security programs throughout the World: Europe $2004-$ Russia. URL: http://www.ssa.gov/policy/docs/prodesc/ssptw.

Kohler, H.-P. and Kohler, I. (2002). Fertility decline in Russia in the early and mid 1990s: the role of economic uncertainty and labour market crisis. European Journal of Population, 18: 233-262.

Kreyenfeld, M. (2001). Employment and fertility - East Germany in the 1990s. Rostock: Universität Rostock. 
Lesthaeghe, R. (1992). Der zweite demographische Übergang in den westlichen Ländern: Eine Deutung. Zeitschrift für Bevölkerungswissenschaften, 18: 313-354.

Lokshin, M. M. (2004). Household child care choices and women's work behavior in Russia. Journal of Human Resources, 39 (4): 1094-1115.

Mroz, T. A. et al. (2004). Monitoring economic conditions in the Russian Federation. Russian Longitudinal Monitoring Survey, 1-28.

OECD (2001). The social crisis in the Russian Federation. OECD - Social Issues, 1-146.

Philipov, D. (2002). Fertility in times of discontinuous societal change: the case of Central and Eastern Europe. MPIDR Working Paper, WP 2002-024.

Shorrocks, A. and Kolenikov, S. (2001). Poverty trends in Russia during the transition, $1-15$.

Szivos, P. and Giudici, C. (2004). Demographic implications of social exclusion in central and eastern Europe. Population Studies, 46: 1-113.

Van de Kaa, D. (1987). Europe's second demographic transition. Population Bulletin, 42: $1-59$.

Veselkova, I. N. and Sagradov, A. (1995). Current demographic sitiuation of Russia. Bevolking en gezin, 1: 97-104.

Vikat, A. et al. (2005). Generations and Gender Survey (GGS): Towards a better understanding of relationships and processes in the life course. Draft.

Vishnevsky, A. G. (1996). Family, fertility, and demographic dynamics in Russia: Analysis and forecast. In: Da Vanzo, J. (eds.), Russia's demographic "crisis", Chapter I, RAND.

Weber, C. and Goodman, A. (1981). The demographic policy debate in the USSR. Population and Development Review, 7 (2): 279-295.

Zakharov, S. V. and Ivanova, E. I. (1996). Fertility decline and recent changes in Russia: on the theshold of the Second Demographic Transition. In: Da Vanzo, J. (eds.), Russia's demographic "crisis", Chapter II, RAND. 
Zakharov, S. V. (1999). Fertility trends in Russia and the European new independent states: crisis or turning point? Population Bulletin, Special Issue 40/41 on "Below Replacement Fertility", United Nations, New York: 292-317. 


\section{Appendix}

Appendix 1: Family Policy in Russia (respectively former Soviet Union) before and after the transition

\begin{tabular}{|c|c|c|c|}
\hline & Until 1980 & 1980s & 1990s \\
\hline $\begin{array}{l}\text { Childbirth } \\
\text { grant }\end{array}$ & $\begin{array}{l}\text { - only for second and } \\
\text { higher order births }\end{array}$ & $\begin{array}{l}\text { - } 50 \text { rubles }(\$ 67.59) \text { for } 1^{\text {st }} \\
\text { child } \\
-100 \text { rubles for } 2^{\text {nd }} \text { and } 3^{\text {rd }} \\
\text { child - for working mothers } \\
\text { - for non working mothers } \\
30 \text { rubles for } 1^{\text {st }}, 2^{\text {nd }} \text {, and } \\
3^{\text {rd }} \text { birth }\end{array}$ & $\begin{array}{l}\text { - lump sum of } 15 \text { times the } \\
\text { monthly minimum wage }\end{array}$ \\
\hline $\begin{array}{l}\text { Maternity } \\
\text { leave }\end{array}$ & \begin{tabular}{|l}
-56 days before and 56 \\
days after childbirth, \\
regardless of the length of \\
employment \\
- after that unpaid \\
maternity leave up to one \\
year after childbirth
\end{tabular} & - former laws adopted & $\begin{array}{l}-70 \text { days before and } 70 \\
\text { days after childbirth (may } \\
\text { be increased by an } \\
\text { additional } 14 \text { or } 40 \text { days in } \\
\text { certain cases) }\end{array}$ \\
\hline $\begin{array}{l}\text { Maternity } \\
\text { benefit }\end{array}$ & & $\begin{array}{l}\text { - partially paid leave of } 35 \\
-50 \text { rubles/month } \\
\text { (regional different) for one } \\
\text { year after childbirth }\end{array}$ & $\begin{array}{l}-100 \% \text { of the insured gross } \\
\text { earnings of the last month } \\
\text { before maternity leave }\end{array}$ \\
\hline $\begin{array}{l}\text { Child care } \\
\text { leave } \\
\text { allowance }\end{array}$ & $\begin{array}{l}\text { - payments only for } 3^{\text {rd }} \text { and } \\
\text { higher-order births (paid } \\
\text { until child's } 15^{\text {th }} \text { birthday }\end{array}$ & $\begin{array}{l}\text { - one year paid leave for } \\
\text { women } \\
\text { - partially paid maternity } \\
\text { leave up to } 18 \text { months } \\
\text { (different in different } \\
\text { regions) }\end{array}$ & $\begin{array}{l}\text { - } 500 \text { rubles }{ }^{5} \text { monthly ( } 70 \\
\text { rubles for the unemployed) } \\
\text { until the child is age } 18 \\
\text { month } \\
-50 \text { rubles per month until } \\
\text { the child is } 3 \text { years old }\end{array}$ \\
\hline $\begin{array}{l}\text { Child sick } \\
\text { leave }\end{array}$ & $\begin{array}{l}\text { - for children up to age } 14 \\
\text { - seven calendar days (10 } \\
\text { for single mothers) } \\
\text { - for children over } 14 \text {, three } \\
\text { day limit per episode of } \\
\text { illness } \\
\text { - no limits in the number of } \\
\text { periods }\end{array}$ & $\begin{array}{l}\text { - full salary sick leave for } \\
\text { families with three or more } \\
\text { children up to age } 16 \text { (law } \\
\text { from 1975) }\end{array}$ & $\begin{array}{l}\text { - benefit is provided for: - } \\
\text { the total period of sickness } \\
\text { - for children under age } 7 \text {, } \\
15 \text { calendar days - for } \\
\text { children under age } 15,7 \\
\text { calendar days - for } \\
\text { children over age } 15\end{array}$ \\
\hline $\begin{array}{l}\text { Child sick } \\
\text { allowance }\end{array}$ & & $\begin{array}{l}\text { - } 50 \% \text { of the full salary for } \\
\text { workers with an } \\
\text { uninterrupted tenure of } \\
\text { under } 3 \text { years to } \\
-100 \% \text { for workers with } 8 \\
\text { or more years of tenure }\end{array}$ & $\begin{array}{l}-60-100 \% \text { of wages for the } \\
\text { first } 7 \text { days of illness } \\
\text { - thereafter } 30 \% \text { of wages } \\
\text { (50\% for single mothers) } \\
\text { until recovery }\end{array}$ \\
\hline Daycare & $\begin{array}{l}\text { - opportunity of } 24 \text { hour } \\
\text { care }\end{array}$ & $\begin{array}{l}\text { - free public childcare } \\
\text { facilities }\end{array}$ & $\begin{array}{l}\text { - no government child care } \\
\text { programs }\end{array}$ \\
\hline Other & $\begin{array}{l}\text { - income tax was altered to } \\
\text { favor families } \\
\text { - families with a monthly } \\
\text { household-per-capita- } \\
\text { income under } 50 \text { rubles - } \\
\text { income supplement of } 12 \\
\text { rubles per month for each } \\
\text { child under age } 8\end{array}$ & & $\begin{array}{l}\text { - child allowance for low } \\
\text { income families: } \\
-70 \text { rubles for each child } \\
\text { from } 18 \text { month to age } 16 \\
\text { (- } 105 \text { rubles if a parent is } \\
\text { evading alimony payments) } \\
\text { - single parents receive } \\
\text { twice the child allowance }\end{array}$ \\
\hline
\end{tabular}

Source: David 1982; ISSA 2004; Lokshin 2004; OECD 2001; Weber \& Goodman 1981

${ }^{5} 100$ rubles $=\$ 3.71$ (July 2006) 
Appendix 2: Number of cases included and excluded from the analysis

Number of female respondents 7,038

Number of respondents with one or more children $\quad 5,929$

Excluded cases:

Twins at first birth $\quad 55$

Stepchildren 13

Adopted children 4

Fostered children $\quad 7$

First child born before age $14 \quad 9$

First or second child born after age 45

First child died before birth of second child 39

Missing cases 1

Absolute number of excluded cases 132

Number of respondents $\quad 5,797$

Number of second births $\quad 2,547$

Source: author's estimations based on the Russian GGS 